Article

\title{
Lab@Home: The Open University of Catalonia Hands-on Electronics Laboratory for Online Engineering Education
}

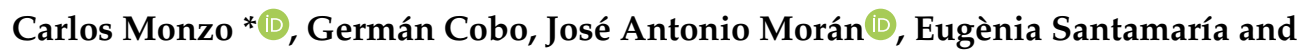 \\ David García-Solórzano (D) \\ Department of Computer Science, Multimedia and Telecommunications, Universitat Oberta de Catalunya, \\ 08018 Barcelona, Spain; gcobo@uoc.edu (G.C.); jmoranm@uoc.edu (J.A.M.); esantamaria@uoc.edu (E.S.); \\ dgarciaso@uoc.edu (D.G.-S.) \\ * Correspondence: cmonzo@uoc.edu
}

Received: 20 December 2019; Accepted: 23 January 2020; Published: 29 January 2020

\begin{abstract}
Practical experimentation is essential for electronics learning. As the acquisition of practical and professional competences in full online scenario is concerned, it is very relevant the use of technology that allows students to carry out hands-on experiments. This paper presents Lab@Home, the Open University of Catalonia (Universitat Oberta de Catalunya, UOC, Barcelona, Spain) hands-on electronics laboratory, which allows online students to carry out practical experiments anywhere and anytime at a reduced cost and with good portability characteristics. Lab@Home features and students satisfaction are analyzed during six consecutive semesters in two different subjects by means of a self-administered questionnaire, showing the benefits of using Lab@Home in the acquisition of the subjects contents and gathering how could be improved students learning experience by using this kind of electronics laboratory.
\end{abstract}

Keywords: electronics; laboratory; online engineering

\section{Introduction}

Laboratories become essential in technological degrees, where the practical experimentation is required to acquire the expected competencies and professional skills [1].

In this regard, the study of electronics technology has been traditionally linked to the use of face-to-face hands-on laboratories. In recent decades there have been technological advances that have opened the door to distance engineering education, being broadly accepted that the quality of these courses is comparable to that of the traditional ones [2]. In this context, the challenge for technical degrees is how to provide the best laboratory experience.

There exist a great number of solutions for virtual (simulation) and remote (real hardware manipulation) laboratories, but the main challenge is making available real hands-on experiences in online education. Thus, there are different approaches that try to give a solution to the practical experimentation needs. The first one is based on simulations (virtual). The use of these resources covers both distance and face-to-face universities [3-5], since these allow students to work with a full time availability resources and offers the possibility of developing low-cost complex experiments.

Secondly, during the last decade many higher education institutions have developed a large number of remote access laboratories on different topics. Thus, proper resources are provided to the students to achieve the expected learning objectives. Some examples of these initiatives are: (i) iLab [6], initiated in the Massachusetts Institute of Technology (MIT) with the aim of sharing real instrumentation among students, which otherwise would be impossible considering the acquiring 
and maintaining devices cost; (ii) Labshare [7], a project funded by the Australian government to create a national network of remote laboratories; and (iii) LiLa [8], a project co-financed by the European Community to promote remote and virtual laboratories in the fields of natural sciences and engineering.

Finally, a variety of resources have been developed with the aim of allowing hands-on experimentation outside of the physical laboratory, and promoting flexibility during the study:

i. Mobile Studio Project [9]: a low-cost solution [10,11] with oscilloscope, function generator, digital multimeter (DMM), reconfigurable digital I/O ports and power supplies.

ii. NI devices like myDAQ [12], Analog Discovery 2-NI Edition [13] or USB-600x [14]. myDAQ is a data acquisition (DAQ) device to measure and analyze live signals on a computer $[15,16]$ providing DMM, oscilloscope, and function generator. Analog Discovery 2-NI Edition is a complete solution with oscilloscope, arbitrary function generator, logic analyzer and pattern generator, network analyzer, and spectrum analyzer functionalities. In addition, NI USB-600x provides basic analog and digital I/O functionality.

iii. StudentEDEA [17]: a low-cost solution for offering the possibility to do electronics operations at home.

iv. Vernier Circuit Board 2 [18]: a basic electricity lab to connect series and parallel circuits, examine the behavior of components, and investigate RLC circuits.

v. Arduino Uno [19]: the simplest version of an open-source platform consisting of a microcontroller, and an Integrated Development Environment (IDE).

The Open University of Catalonia (Universitat Oberta de Catalunya, UOC), as a fully online university (eLearning) [20], proposes a complete laboratory experience based on combining simulation, remote and hands-on laboratories in the Bachelor and Master of Telecommunications Engineering degrees (BTE and MTE respectively). These are two official degrees adapted to the European Higher Education Area (EHEA) [21] with roughly 1000 students.

Regarding this paper, it is aimed to present Lab@Home, the UOC's electronics hands-on laboratory proposal to let students acquire the required practical competencies and professional skills related to Telecommunications Engineering. The main points to be dealt with this work are:

1. Presentation of Lab@Home and how it can improve the existing hands-on laboratories taken into account the fully online education context where it is used, and important issues like flexibility and cost.

2. Description of the main features of Lab@Home and its use in online engineering education.

3. Analysis and validation of the utility and potential use of Lab@Home by means of a self-administered questionnaire sent to students.

The rest of the paper is organized as follows. Lab@Home system is described in Section 2, showing its features, and a comparison with the state-of-the-art. Section 3 presents the evaluation of Lab@Home carried out by online students of two different subjects over six consecutive semesters. Finally, the conclusions and future work are shown in Section 4.

\section{Lab@Home}

\subsection{Lab@Home Overview}

This section presents the fully system designed, developed and evaluated by UOC, taking into account the necessity of students of acquiring practical competences in electronics related subjects in online engineering education. Given that, three main challenges to be solved are presented next.

i. The proposal has to be a complete system, with similar features that could be found in a traditional electronics laboratory. 
ii. The proposal has to be a reduced cost system for experimenting: no high cost equipment is able to be sent to students.

iii. The proposal needs to have good portability characteristics: online students needs to study at home, library or wherever.

Taking into account the challenge to be solved, the methodology applied during the proposal conceptualization has been based on prototyping research method for information systems and computing [22]. This kind of methodology let to conduct a technological development, be assessed and improved.

In the rest of this section, on the one hand Section 2.2 describes Lab@Home taking into account its main technical characteristics. On the second hand, in Section 2.3, Lab@Home is compared with the state-of-the-art initiatives presented in Section 1 considering the previous challenges to be dealt with: features, cost, and portability.

\subsection{Lab@Home Description}

Lab@Home is the assembly and measurement system for electronic circuits developed by UOC, and protected by an utility model, for the learning of electronics concepts in telecommunication engineering degrees [23]. Lab@Home is mainly a hardware platform (Figure 1) connected to a computer that provides the main features of a traditional electronics laboratory at a reduced cost (the current cost for UOC's students is about \$65): circuits assembling, testing, measurement procedures and signal acquisition.

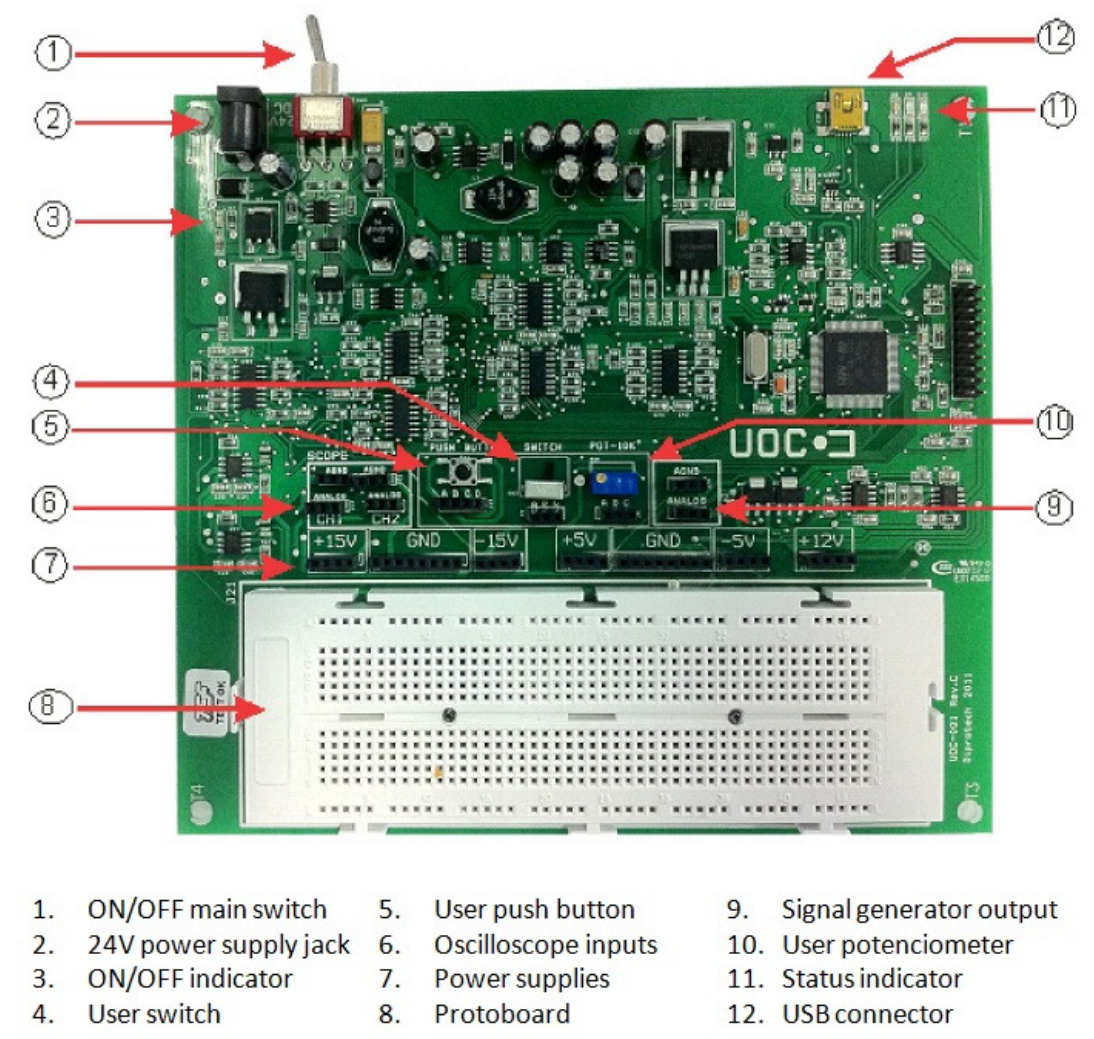

Figure 1. Lab@Home platform.

Figure 2 presents the block diagram of the whole system, showing how the platform is fed by means of a power supply connected to the electrical grid, the different parts of the system, and the connection to a PC to carry out the overall control. This block diagram is described as follows:

- Power supply module. All the voltage levels required by the rest of modules are obtained from the power outlet and using both switched power supplies and linear regulators. 
- Microcontroller module. It comprises the microcontroller that rules over the whole platform, as well as the external memory where the firmware of the board is held.

- USB module. It allows the communication between the microcontroller module and the external computer, from which the user can handle, via software, the signal generation and acquisition functionalities provided by the platform.

- Status LEDs module. It indicates the system status (e.g., ON, OFF, ready, loading firmware, no communication, etc.) by means of four differently colored LEDs.

- Signal generation module. It is connected to the analog output channel of the microcontroller. It allows generating periodic analog signals and to bring them to the user module.

- Signal acquisition module. It is connected to the two analog input channels of the microcontroller. It allows acquiring simultaneously two different signal measurements from the user module.

- User module. It is the area of the platform where the user can build and measure electronic circuits. It integrates a protoboard, a switch, a potentiometer, and a push button, along with all the I/O connectors to the different voltage sources and both signal generation and acquisition modules.

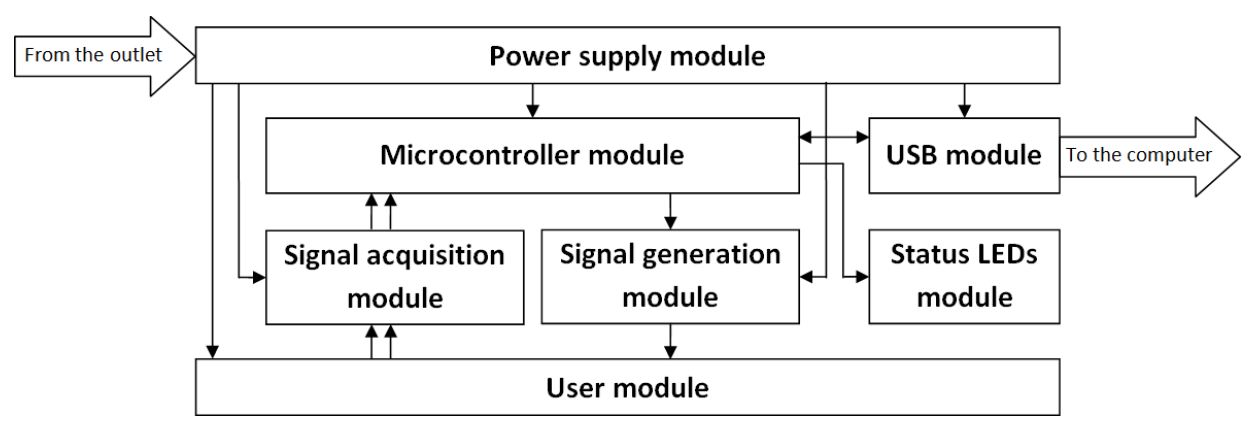

Figure 2. Block diagram of Lab@Home.

In terms of Lab@Home functionalities and technical technical characteristics, they are presented next:

- In-Out interfaces. It is connected to the electrical grid by means of a $24 \mathrm{~V} / 500 \mathrm{~mA}$ power supply. Moreover, devices control is performed by using a mini-USB connector connected to a PC. Finally, four LEDs show system status.

- Working area. Users have available an integrated protoboard with all the available modules connected to it: dynamic components (e.g., potenciometer), DC power supplies, and signal generation and measurement devices.

- DC power supplies. There are available $\pm 5 \mathrm{~V}, 12 \mathrm{~V}$ and $\pm 15 \mathrm{~V}$ power supplies, with a maximum output current $100 \mathrm{~mA}$ in each one.

- Signal generation. A periodic function generator (sinusoidal, square, triangular, saw, arbitrary and sweep) is controlled from a PC (Figure 3), with a voltage range of $\pm 15 \mathrm{~V}$ and a maximum output current of $100 \mathrm{~mA}$. It provides all the typical features (i.e., amplitude, frequency, duty cycle and offset). The maximum sampling rate is $351 \mathrm{kHz}$ (board hardware limitations).

- Voltage measurement. A two channels digital oscilloscope is available. It is controlled from a PC (Figure 4) providing the same features of a commercial model: volt and time division, level of trigger, cursors, acquisition modes, measure mode and math menu.

In order to understand better what kind of experiments can be carried out with Lab@Home, students have to design a circuit using 555 Oscillator, taking into account that we want to study signal amplification using transistors. In addition, students have to design a band-pass filter using RLC components provided by the kit. This experiment can be performed by using kit components, the working are for experimentation and all devices implemented in Lab@Home. 


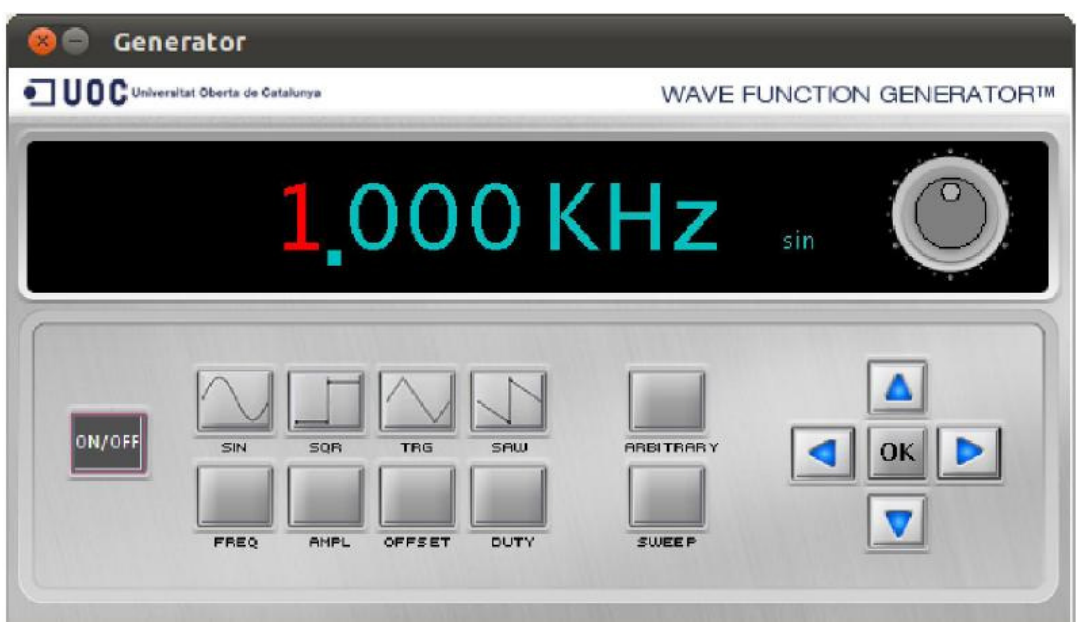

Figure 3. Periodic function generator.

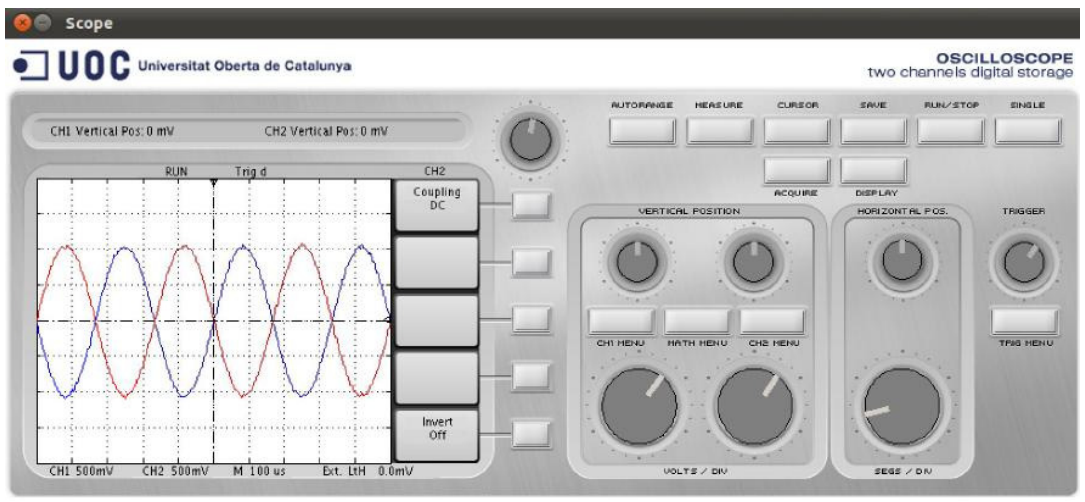

Figure 4. Digital oscilloscope.

\subsection{Lab@Home in the State-of-the-Art}

As it has been presented in Section 2.2, Lab@Home is mainly a hardware platform connected to a computer that provides the main features of a traditional electronics laboratory at a reduced cost, and under good conditions for portability-all elements are available in a working area. A comparative table among the state-of-the-art of electronics hands-on laboratories presented in Section 1 and Lab@Home is shown in Table 1.

Table 1. Comparison among Lab@Home and state-of-the-art electronics hands-on laboratories.

\begin{tabular}{|c|c|c|c|c|c|}
\hline Initiative & DC Power Supply & Signal Generation & Signal Measurement & Working Integrated Area & Cost \\
\hline NI myDAQ kit & $5 \mathrm{~V}, \pm 15 \mathrm{~V}$ & Function generator & Oscilloscope, DMM & No & $\$ 400$ \\
\hline Vernier Circuit Board 2 & $4 \mathrm{~V}^{* * *}$ & - & - & Electronic components & $\$ 155$ \\
\hline Arduino Uno & $3.3 \mathrm{~V}, 5 \mathrm{~V}$ & - & - & No & $\$ 25$ \\
\hline Lab@Home & $\pm 5 \mathrm{~V}, 12 \mathrm{~V}, \pm 15 \mathrm{~V}$ & Function generator & Digital oscilloscope & Protoboard, electronic components & $\$ 65^{* * * *}$ \\
\hline
\end{tabular}

${ }^{*}$ Currently discontinued. ${ }^{* *}$ Availability depending on model. ${ }^{* * *}$ Available when an external module is used. ${ }^{* * *}$ Current cost for UOC's students.

If the three main needed characteristics introduced in Section 2.1 are taken into account, i.e., a complete solution at a reduced cost and with good portability capabilities, we can conclude that 
Lab@Home is the most complete solution among the stat-of-the-art of hands-on electronics laboratory for online learning. Comparing each main benefit of Lab@Home in a separated way, the following conclusions can be reached:

1. Power supplies availability. Lab@Home has the most variability of DC power supplies, allowing to feed more circuits with different needs.

2. Signal generation and voltage measurement. Signal generation and measurement is a key feature to develop experiments in a hands-on electronics laboratory. In this way, Lab@Home integrates function generator and oscilloscope in the same platform, being the best option like Mobile Studio Project, NI myDAQ kit and Analog Discovery 2-NI Edition initiatives.

3. Integrated working area. Lab@Home is the only platform with an integrated working area for creating your own experiments. Another option is Vernier Circuit Board 2 but experiments in working area are limited to the available electronic components.

4. Portability. Lab@Home has good conditions for portability due to all integrated features. Some of the state-of-the-art initiatives like NI USB600-x, Vernier Circuit Board 2, StudentEDEA or Arduino Uno need external devices to be available DC power supplies, generate signals and/or perform measures, or create experiments.

5. Cost. Lab@Home has the lower cost among all the state-of-the-art options, except if Arduino Uno is considered.

Taking into account all features, Lab@Home is the more complete reduced cost option with the best variability of DC power supplies, with signal generator/measurement, an integrated working area and good conditions for portability. All these benefit make this solution an ideal option for online learning where students have to use their own resources from anywhere during the learning process. In UOC, as an fully online University, no physical access is possible to traditional laboratories and the use of a hands-on laboratory like Lab@Home let combining experimental and theoretical knowledge during the study.

\section{Lab@Home Evaluation}

\subsection{Evaluation Design}

Lab@Home has been used by 517 students over six consecutive semesters, in two different subjects belonging to the Bachelor of Telecommunications Engineering (BTE) degree at UOC: Circuits Theory (CT) and Electronics Technology (ET). These subjects are the introduction to the analog electronics field. The use of Lab@Home in practical activities was mandatory for all students to pass the course.

At the beginning of the semester, all students have available the following hands-on laboratory kit to perform the practical activities: i) Lab@Home system; ii) a digital multimeter, and iii) a set of different electronic components (e.g., transistors).

At the end of each semester, a self-administered questionnaire [22] was sent to students, asking the next questions, to assess their experience using Lab@Home:

Q1. Do you consider that the use of Lab@Home favors the assimilation of the theoretical contents included in the subject?

Q2. Would you consider advisable to extend the use of Lab@Home to other subjects?

Q3. What other kind of functionalities would be convenient to be provided by a hands-on laboratory like Lab@Home?

The first question, with answers in the range of 1 (completely disagree) to 5 (completely agree), is related to the benefits of using Lab@Home in the acquisition of the contents of these subjects. The second one, with answers in the range of 1 (completely disagree) to 5 (completely agree), is asking about the utility of extending the use of the Lab@Home to other subjects (Q2). Finally, the third 
question is an open-answer question with the aim of knowing what kind of functionalities could be useful to be included in a hands-on laboratory like Lab@Home (Q3).

\subsection{Evaluation Results}

According to Table 2, a total number of 517 students were enrolled in CT and ET subjects during six consecutive semesters, and 209 of them answered the available self-administered questionnaire (more than a $40 \%$ of participation).

Table 2. Number of students enrolled in Circuits Theory (CT) and Electronics Technology (ET) per semester and number of student answering the the self-administered questionnaire (in brackets).

\begin{tabular}{cccccccc}
\hline Subject & Semester $\mathbf{1}$ & Semester $\mathbf{2}$ & Semester $\mathbf{3}$ & Semester $\mathbf{4}$ & Semester $\mathbf{5}$ & Semester $\mathbf{6}$ & Total \\
\hline CT & $27(8)$ & $112(43)$ & $0(0)$ & $112(43)$ & $5(2)$ & $107(35)$ & $363(131)$ \\
ET & $28(18)$ & $0(0)$ & $57(35)$ & $0(0)$ & $69(25)$ & $0(0)$ & $154(78)$ \\
Total & $55(26)$ & $112(43)$ & $57(35)$ & $112(43)$ & $74(27)$ & $107(35)$ & $517(209)$ \\
\hline
\end{tabular}

Firstly, Q1 question results are presented in Figure 5, showing the boxplots related to the benefits of using Lab@Home in the acquisition of the subjects contents. The most answers obtained a score between 4 (very agree) and 5 (completely agree), with a median value of 5 (completely agree). Therefore, these results show that the most of students thought that the use of Lab@Home had facilitated the understanding of the concepts by means of practical experimentation.

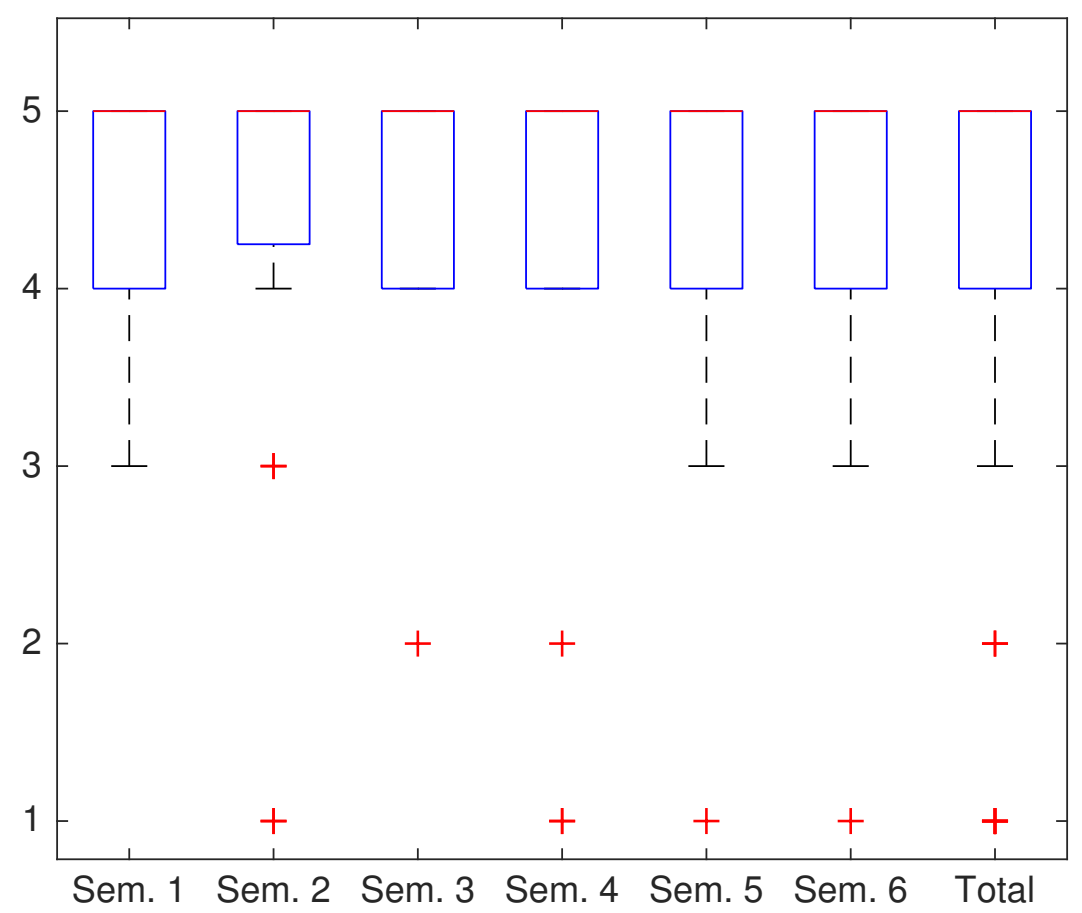

Figure 5. Q1 evaluation results.

Secondly, regarding Q2 question assessment, Figure 6 presents the boxplots for the agreement about extending the use of Lab@Home to other subjects. Notice that the most answers were between 3 (agree) and 5 (completely agree), with a median value of 4 (very agree). Therefore, students agreed with extending the use of Lab@Home to other subjects. Although Lab@Home was very well valued, 
some limitation of the system (e.g., available functionalities), could be a reason for the detected variability in these results. This hypothesis can be analyzed by means of the Q3 open-question, which is discussed below.

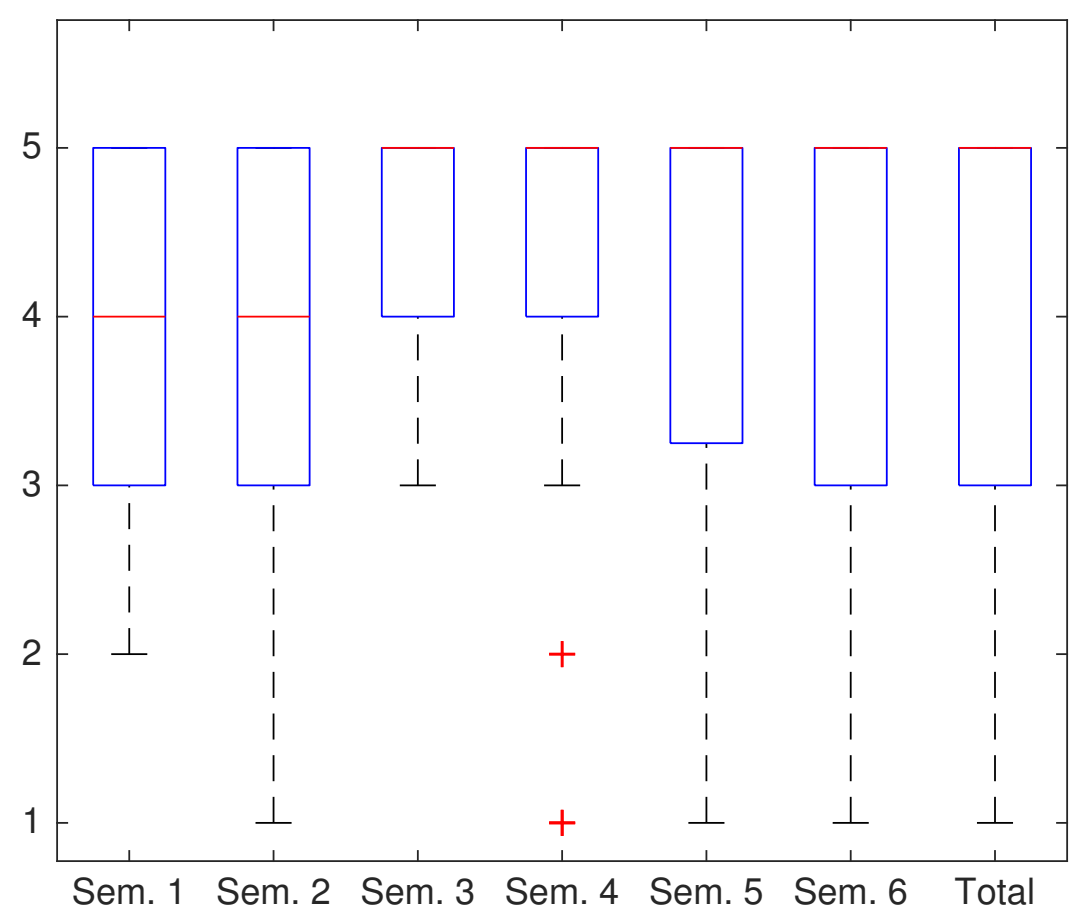

Figure 6. Q2 evaluation results.

Finally, results for Q3 question are presented in Table 3, where each student was able to indicate the functionalities they would like to find in a system like Lab@Home. As it is shown in Table 3, the most preferred functionalities were spectrum and impedance analyzer ( $60.89 \%$ and $41.34 \%$ respectively). Moreover, there was a great interest related to modulation generation $(40.78 \%)$ and analysis $(34.08 \%)$. Finally, there was an interest related to signal measurement using more extended functionalities like multimeter $(39.11 \%)$ or similar: amperemeter $(31.28 \%)$, voltmeter $(30.73 \%)$, wattmeter $(22.35 \%)$, and ohmmeter $(20.67 \%)$.

Table 3. Q3 sorted answers for convenient Lab@Home functionalities. Each column represents the number of students that selected each functionality per semester and the total percentage.

\begin{tabular}{cccccccc}
\hline Functionality & Semester 1 & Semester 2 & Semester 3 & Semester 4 & Semester 5 & Semester 6 & Total \\
\hline Spectrum analyzer & 10 & 22 & 16 & 24 & 13 & 24 & $60.89 \%$ \\
Impedance analyzer & 7 & 21 & 14 & 13 & 6 & 13 & $41.34 \%$ \\
Modulation generator & 6 & 19 & 15 & 13 & 7 & 13 & $40.78 \%$ \\
Multimeter & 7 & 15 & 12 & 14 & 8 & 14 & $39.11 \%$ \\
Modulation analyzer & 6 & 19 & 13 & 8 & 7 & 8 & $34.08 \%$ \\
Amperemeter & 7 & 12 & 11 & 10 & 6 & 10 & $31.28 \%$ \\
Voltmeter & 9 & 10 & 10 & 11 & 4 & 11 & $30.73 \%$ \\
Wattmeter & 2 & 12 & 9 & 6 & 5 & 6 & $22.35 \%$ \\
Ohmmeter & 4 & 9 & 5 & 8 & 3 & 8 & $20.67 \%$ \\
\hline
\end{tabular}


According to results shown in Table 3, students would appreciate having some complex functionalities, some of them related to signal analysis (spectrum, impedance and modulation) and generation (modulation). These results can be linked to the fact that in the current Lab@Home already exists both digital oscilloscope (analyzer) and signal generation (generator) functionalities, so they want new and advanced ones. In addition, in terms of multimeter and similar functionalities, a real multimeter was delivered to the students in the practice kit. Thus, the necessity of this kind of functionalities is not so important, although some students could prefer the integration of all functionalities in the same system.

\section{Conclusions and Future Work}

Practical experimentation is essential in technological degrees to acquire the required practical competences. Moreover, when this issue is posed from the perspective of distance learning it becomes a real challenge to be resolved. This work presents Lab@Home, the hands-on electronics laboratory of the Open University of Catalonia (Universitat Oberta de Catalunya, UOC), intended to let students experiment anywhere and anytime with real hardware in a fully online telecommunications engineering learning context.

Lab@Home is an assembly and measurement system aimed to the learning of electronics concepts in telecommunications engineering related degrees. It consists of a hardware platform connected to a computer that provides the main features of a traditional electronics laboratory at a reduced cost. During this work has been shown the benefits of using it regarding the use of the state-of-the-art hands-on laboratories. In addition, this paper presents the system as it is sent to online UOC's telecommunications engineering students along with a complete kit aimed to the acquisition of practical competences related to electronics technology, complementing the concepts worked on the subjects.

In order to evaluate the utility of Lab@Home in a real context, a self-administered questionnaire was performed by the students of two subjects at the end of six consecutive semesters. Results indicate that Lab@Home helps students to assimilate the theoretical concepts according to the needs of them. In addition, students consider advisable to extend the use of this laboratory to other subjects. Furthermore, they also propose how to improve a hands-on laboratory by adding new functionalities.

This last issue, related to new functionalities, is linked to the future work, since new laboratory developments were planned during the evaluation of Lab@Home. Nowadays, it is available a new version of this hands-on laboratory to improve the laboratory features and increase students' learning experience satisfaction. Moreover, it has been obtained a property protection by means of a patent [24]. Thus, we are currently working in the use and assessment of the evolution of Lab@Home.

\section{Patents}

One utility model and one patent have been derived from the conducted work in hands-on electronics laboratory:

- Fundació per a la Universitat Oberta de Catalunya, "Assembly and measurement system of electronic circuits,"Spanish Patent ES 1077336 U, 2012.

- Fundació per a la Universitat Oberta de Catalunya, "Device for mounting and measuring at least one electronic circuit and procedure, computer program, system and computer system to control the device," Spanish Patent ES2 636 650, 2018.

Author Contributions: Conceptualization, C.M., G.C., J.A.M. and E.S.; funding acquisition, E.S.; investigation, C.M. and G.C.; resources, J.A.M. and E.S.; software, D.G.-S.; supervision, C.M. and G.C.; validation, C.M. All authors have read and agreed to the published version of the manuscript.

Funding: This research received no external funding.

Acknowledgments: The authors would like to thank Universitat Oberta de Catalunya for its support in the development of this work as well as Diprotech S.L. for its collaboration. 
Conflicts of Interest: The authors declare no conflict of interest.

\section{Abbreviations}

The following abbreviations are used in this manuscript:

BTE Bachelor of Telecommunications Engineering

CT Electronics Technology

ET Circuits Theory

DAQ Data Acquisition

DMM Digital Multimeter

UOC Open University of Catalonia (Universitat Oberta de Catalunya)

\section{References}

1. Gustavsson, I.; Nilsson, K.; Zackrisson, J.; Garcia-Zubia, J.; Hernandez-Jayo, U.; Nafalski, A.; Nedic, Z.; Gol, O.; Machotka, J.; Pettersson, M.; et al. On objectives of instructional laboratories, individual assessment, and use of collaborative remote laboratories. IEEE Trans. Learn. Technol. 2009, 2, 263-274. [CrossRef]

2. Feisel, L.; Rosa, A. The Role of the Laboratory in Undergraduate Engineering Education. Int. J. Eng. Educ. 2005, 94, 121-130. [CrossRef]

3. Jung, I. Quality Assurance Survey of Mega-Universities. In Lifelong Learning and Distance Higher Education; Christopher, M., Varoglu, Z., Eds.; UNESCO-COL: Paris, France; Vancouver, BC, Canada, 2005.

4. Kidney, G.; Cummings, L.; Boehmt, A. Toward a Quality Assurance Approach to E-Learning Courses. Int. J. E-Learn. 2007, 6, 17-30.

5. Swedish National Agency for Higher Education. E-Learning Quality Aspects and Criteria for Evaluation of E-Learning; Swedish National Agency for Higher Education: Stockholm, Sweden, 2008.

6. iLab Project. Available online: http:/ / icampus.mit.edu/projects/ilabs/ (accessed on 10 February 2019).

7. Labshare Project. Available online: http://www.labshare.edu.au/project/ (accessed on 10 February 2019).

8. LiLa Project. Available online: http://www.lila-project.org/ (accessed on 10 February 2019).

9. Mobile Studio Project. Available online: http://www.mobilestudioproject.com/ (accessed on 10 February 2019).

10. Millard, D. Coming Soon to a Desktop Near You. Available online: https://www.yumpu.com/ en/document/read/3424151/coming-soon-to-a-desktop-near-you-rensselaers-backwrite (accessed on 2 December 2019).

11. Connor, K.; Ferri, B.; Meehan, K. Models of Mobile Hands-On STEM Education. In Proceedings of 2013 American Society for Engineering Education Annual Conference and Exposition, Atlanta, GA, USA, 23-26 June 2013.

12. National Instruments. Ni myDAQ User Guide and Specifications. Available online: https://mil.ufl.edu/ 3111/docs/myDAQ/myDAQ_user_guide_and_specs.pdf (accessed on 2 December 2019).

13. Instruments, N. Analog Discovery 2-NI Edition Overview. Available online: https://www.ni.com/pdf/ manuals / AnalogDiscovery2NIDatasheet.pdf (accessed on 2 December 2019).

14. National Instruments. NI USB-6008/6009 User Guide. Available online: http://www.ni.com/pdf/manuals / 371303n.pdf (accessed on 2 December 2019 ).

15. Walters, M.; Luther, E.; Dinolfo, J. Do Engineering-Anywhere, Anytime. In Proceedings of the Canadian Engineering Education Association (CEEA12), Winnipeg, MB, Canada, 17-20 June 2012; pp. 1-4.

16. Walters, M. Using low-cost technology and relevant challenges to encourage and retain engineering students. In Proceedings of the 2012 2nd Interdisciplinary Engineering Design Education Conference (IEDEC), Sanata Clara, CA, USA, 19 March 2012; pp. 121-123.

17. Ursutiu, D.; Dumitru, I.; Samoila, C. Student educational device for electronic applications (StudentEDEA). In Proceedings of 2013 International Conference on Interactive Collaborative Learning (ICL), Kazan, Russia, 25-27 September 2013; pp. 552-555.

18. Vernier. Available online: https://www.vernier.com/products/accessories/vcb2/ (accessed on 10 February 2019).

19. Arduino Uno. Available online: https://store.arduino.cc/arduino-uno-rev3 (accessed on 10 February 2019). 
20. Gros, B.; Lara, P.; García, I.; Mas, X.; López, J.; Maniega, D.; Martínez, T. The UOC's Educational Model: Evolution and Future Perspectives; Universitat Oberta de Catalunya: Barcelona, Spain, 2009.

21. Bologna Follow-Up Group Secretariat. The European Higher Education Area (EHEA). 2014. Available online: http:/ / www.ehea.info/ (accessed on 2 December 2019).

22. Oates, B.J. Researching Information Systems and Computing; SAGE Publications Ltd.: London, UK, 2006.

23. Fundació per a la Universitat Oberta de Catalunya. Assembly and Measurement System of Electronic Circuits. Spanish ES 1077336 U, 19 September 2012.

24. Fundació per a la Universitat Oberta de Catalunya. Device for Mounting and Measuring at Least One Electronic Circuit and Procedure, Computer Program, System and Computer System to Control the Device. Spanish ES2636650, 20 July 2018.

(C) 2020 by the authors. Licensee MDPI, Basel, Switzerland. This article is an open access article distributed under the terms and conditions of the Creative Commons Attribution (CC BY) license (http:// creativecommons.org/licenses/by/4.0/). 